\title{
Effect of Extensometer Usage on Obtaining the Force- Displacement Curve of the Adhesively Single Lap Joint
}

\author{
Ahmet Çalık ${ }^{*} \mathbb{( D}$, Salih Akpınar ${ }^{2}$ (i) \\ 'Dept. of Mechanical Eng., Mersin University, 33343 Mersin, TURKEY \\ ${ }^{2}$ Dept. of Mechanical Eng., Erzurum Technical University, 25050 Erzurum, TURKEY
}

\begin{abstract}
Structural adhesively bonded joints are frequently used in many areas spearheaded by the industries such as automotive, marine space, and aviation due to the great advantages they provide. Besides, load capacities of adhesively bonded joints which have different geometries, are generally determined experimentally. Being compatible of experimental and numerical analysis of adhesively bonded joints in the means of both load carrying capacity and displacement has a great importance. But, one of the most common problems in comparison of experimental and numerical analyses is in spite of the coherence of experimental and numerical analyses in load carrying capacity, it is observed that in the means of the displacement analysis, there is incompatibility between those analyses. In the present study, force-displacement curves of the single-lap cohesively bonded joints are obtained experimentally by using both strokes of two different tensile test machines which have identical calibrated load cells and video extensometer. Experimentally obtained result was compared with numerical analysis. In the experiments, AA2024-T3 aluminium and two-component Araldite 2015 were used as adherend and adhesive, respectively. As a result, there is considerable difference between the force-displacement curves of the single-lap overlap joints which obtained experimentally from stroke and video extensometer. Also, being new or old of the tensile test machines which have identical calibrated load cells varies the displacement curve of the joint. When the experimental data were compared with the results of the numerical analysis, it is concluded that, obtaining the force-displacement curves of joints by using video extensometer is more accurate.
\end{abstract}

Keywords: Bonding, Single-Lap Overlap Joint, Tensile Test, Video Extensometer, Mechanical Properties

\section{INTRODUCTION}

Even though the usage of industrials adhesives is novel, with the developments increasingly in the areas such as aviation and automotive, industrial adhesives are replacing the conventional joining methods such as welding and riveting. Adhesively bonded joints provide many advantages such as not causing the crystal structure changes due to the melting and stress concentrations unlike the other conventional methods, bonding under the melting points, and also obtaining cleaner and smoother surfaces [1-3].

Numerical analysis of adhesively bonded joints is extremely important for comparison of experimental data and numerical data, and predicting the effects of other parameters concerning the joint without experiments. For that purpose, different techniques (analytical modelling and numerical solution) were used in the past to predict the force and stress distributions of composite joints used as adhesive. In literature, there are different analytical models used for analysis of adhesively bonded joints [4-6].

In order to ensure that the stress-free boundary conditions would be satisfied at the free ends, some researchers employed two-dimensional elasticity theory in conjunction with the variational method, such as minimum strain method $[7,8]$ and the principle of complementary energy method [9].

Numerical methods present a general method for analysis of loading conditions and free geometries. Among the numerical methods, finite elements methods (FEM) have been frequently used for analysis of the adhesively bonded joints, and in the literature, there are many analysis studies which are conducted by using finite element method [9-19].

Yet, in recent years, Cohesive Zone Material (CZM) method which is frequently used for analysis of adhesively bonded joints is used. The stress that causes the failure of the adhesively bonded joints is the peel stresses which form in the ends of the overlap regions. The peeling stresses forms in the adhesive, causes the flaws, with the sudden propagation of
* Corresponding authour

Email: ac@mersin.edu.tr 
those flaws through the center, the failure occurs. To simulate this phenomenon which occurs in the adhesion region in the numerical analysis accurately, adhesion region should be modelled via CZM. There are many numerical analysis studies in the literature that conducted using the CZM [20-24] fatigue characteristics of single-lap joints (SLJ.

In spite of the coherence of experimental and numerical analyses in load carrying capacity, it is observed that in the means of the displacement analysis, there is incompatibility between those analyses [25-27]aerospace or aeronautical.

In the present study, single-lap joints were fabricated by using AA2024-T3 as material and two-component Araldite 2015 as adhesive. Force-displacement curves of the single-lap adhesively bonded joints were obtained from strokes of two different tensile test machines which have identical calibrated load cells and video extensometer. The obtained experimental data was compared with the numerical analysis data of the same joint.

\section{MATERIAL AND METHOD}

In the study, two-component Araldite 2015 produced by Huntsman (Basel, Switzerland) was used as adhesive material. AA2024-T3 aluminium alloy which is widely used in aviation and automotive industries due to the light weight, processability, good physical and mechanical properties and high corrosion resistance was used as adherend material [28].

Table 1. Mechanical properties of AA2024-T3 aluminium allay and Araldite 2015 adhesive

\begin{tabular}{|c|c|c|}
\hline & Araldite 2015 & AA2024-T3 \\
\hline$E(M P a)$ & $1834^{ \pm 53}$ & $70600^{ \pm 240}$ \\
\hline$n$ & 0.33 & 0.33 \\
\hline$s_{t}(\mathrm{MPa})$ & $21.4^{ \pm 1.1}$ & $485^{ \pm 15}$ \\
\hline$e_{t}(\%)$ & 4.7 & 18 \\
\hline
\end{tabular}

In the study, force-displacement curves of the single-lap overlap joint were studied both experimentally and numerically. The joint geometry and the parameters used in the experimental study were given in Table 2 and Figure 1. Geometries of the single-lap joints were divided into 4 categories according to displacement measurement method and tensile test machine.

Table 2. Parameters used in the experimental study

\begin{tabular}{|c|c|c|}
\hline Type & Obtained Displacement & Tensile Test Machine \\
\hline Type-I & Stroke & Old \\
\hline Type -II & Video Extensometer & Old \\
\hline Type -III & Stroke & New \\
\hline Type -IV & Video Extensometer & New \\
\hline
\end{tabular}

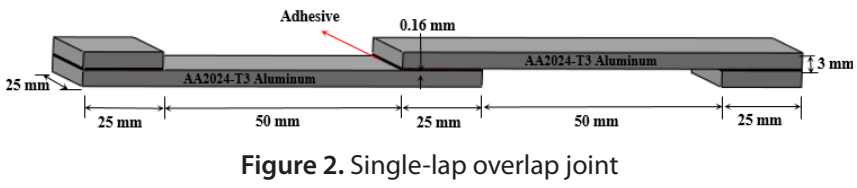

For using in joint specimens, specimen was cut with precision saw in 25x11.5 mm dimensions from AA2024-T3 whi- ch has $4.85 \mathrm{~mm}$ thickness (Figure 1). Afterwards, surface processing needs to be done since the performance of the bonded joints depend on the surface preparation processes. Therefore, wastes such as oil, grease, dirt and dust on the specimen surface were cleaned via 600 grade sandpaper. Then, via 1000 grade sandpaper, scratches on the specimen were removed. Specimens were washed with tap water and detergent and immersed in to acetone bath. The specimens taken out from the acetone bath were completely evaporated in an oven at $60^{\circ} \mathrm{C}$, in this way surface preparation before the bonding process was completed.

The mold in Figure 3a was utilized in order to maintain the position of the bonding materials, adjust the adhesive thickness and overlap length in desired dimensions, and to apply uniform pressure on the joint specimens. Adhesive was applied to overlap regions by aid of a straightedge, and in order to obtain $0.16 \mathrm{~mm}$ bonding thickness, $0.16 \mathrm{~mm}$ thick metal pieces were placed to free ends of the specimens. Aluminium mold apparatuses which have same dimensions with specimens were placed to maintain the overlap lengths of the specimens and to provide uniform pressure. Then, placing the specimens to hot press, curing was performed under a pressure of $0.15 \mathrm{MPa}$ for $120 \mathrm{~min}$ at $70{ }^{\circ} \mathrm{C}$ (Fig. 3b).

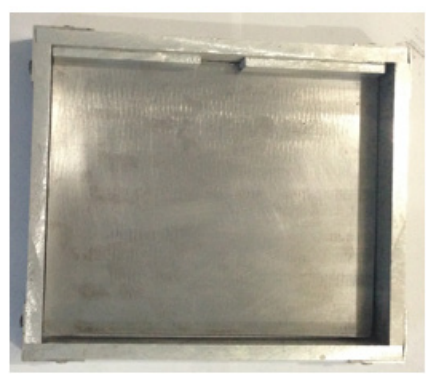

a)

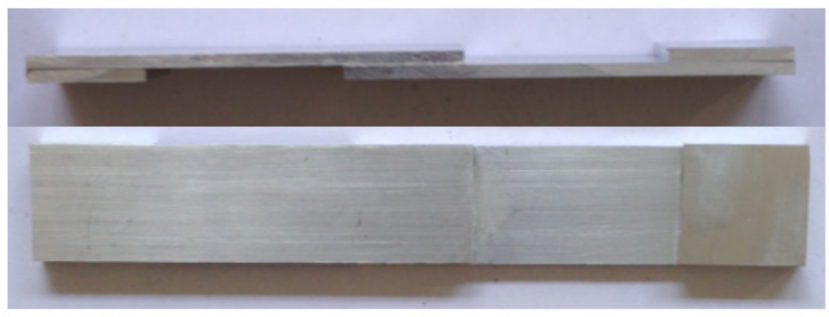

b)

Figure 3. a) Bonding fabrication mold, b) Bonding specimens after curing

A total of 12 single-lap bonding specimens were produced from each bonding configuration, including three samples. The tensile tests of the adhesively bonded joints were performed with two different tensile test machines under $1 \mathrm{~mm} /$ min crosshead speed. The first of these machines is computer controlled universal tensile test device Shimadzu AG-I (Japan) which is recently calibrated and being used actively for 10 years (the old one) in Atatürk University (Figure 4a). And the second is the computer controlled universal tensile test device Instron-5982 (USA) which is also recently calibrated and being used almost for one year (the new one) in Erzurum Technical University (Figure 4b).

In the study, force-displacement curves of the joints were 
obtained from both strokes of the test devices and video extensometers. As depicted in Figure 5, in order to obtain displacement curves from the video extensometers measurement tapes were placed on the joint specimens.
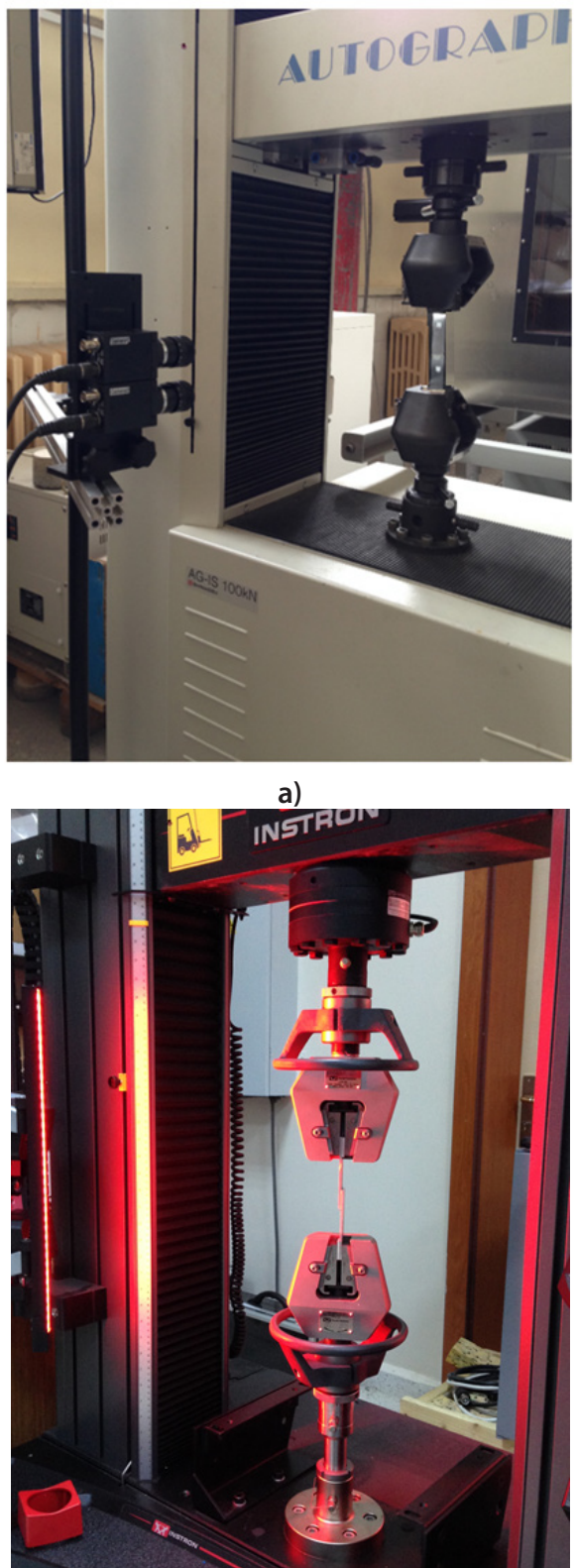

b)

Figure 4. a) Shimadzu AG-I (Japan) universal tensile test device (old), b) Instron-5982 (USA) universal tensile test device (new).

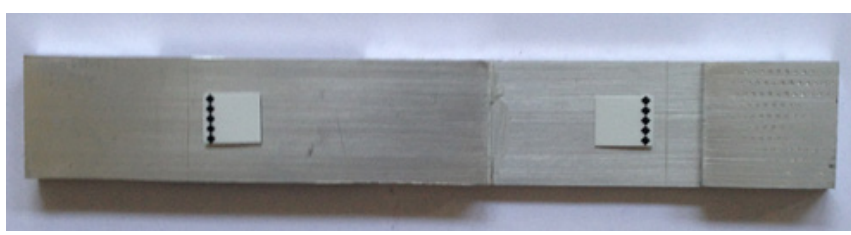

Figure 5. The placement of the measurement tapes on the joint specimen.

The specimen dimensions, loading and boundary conditions used in finite element analyses were same with the experimental study, and the analyses were performed via ANSYS 16 package programme modelling 3D. In 3D analyses, both adhesive and adherend materials were modelled using elements having three degree of freedom and 20 nodes (Solid 186), and the mechanical properties given in Table 1 utilized to model the both adhesive and adherend materials.

Also, for the adhesive layer in numerical analysis Cohesive Zone Material (CZM) model was utilized and the CZM parameters of the adhesive material are given in Table 2. Here in, $G_{I C}$ (the tensile critical strain energy release rate) was obtained from the experiment of the double cantilever beam joint and $\mathrm{G}_{\text {IIC }}$ (the shear critical strain energy release rate) was obtained from the thick adherend shear test.

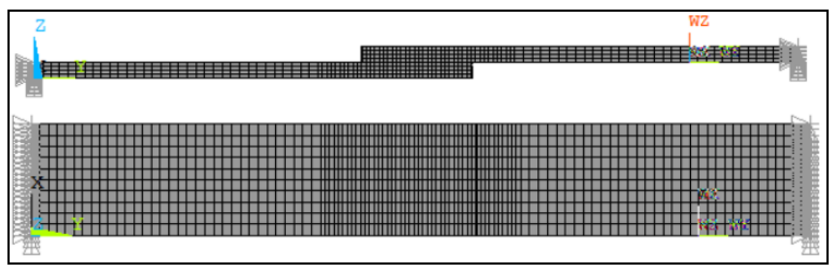

Figure 6. Finite element model of the single-lap overlap joint

Table 3. Properties of the adhesive for the CZM model

\begin{tabular}{|c|c|c|c|}
\hline$(\mathrm{MPa})$ & $\mathrm{G}_{\mathrm{IC}}(\mathrm{N} / \mathrm{mm})$ & $(\mathrm{MPa})$ & $\mathrm{G}_{\mathrm{IIC}}(\mathrm{N} / \mathrm{mm})$ \\
\hline 20.8 & 0.48 & 18.3 & 5.28 \\
\hline
\end{tabular}

\section{RESULTS AND DISCUSSION}

Three specimens for each adhesively bonded single-lap joint types (Type-I, Type-II, Type-III and Type-IV) were tested and according the average of these specimens force-displacement curves were obtained. When the graphs given in Figure 7 are examined, it is seen that the force obtained from both the strokes and the extensometers of the both devices are close to each other.
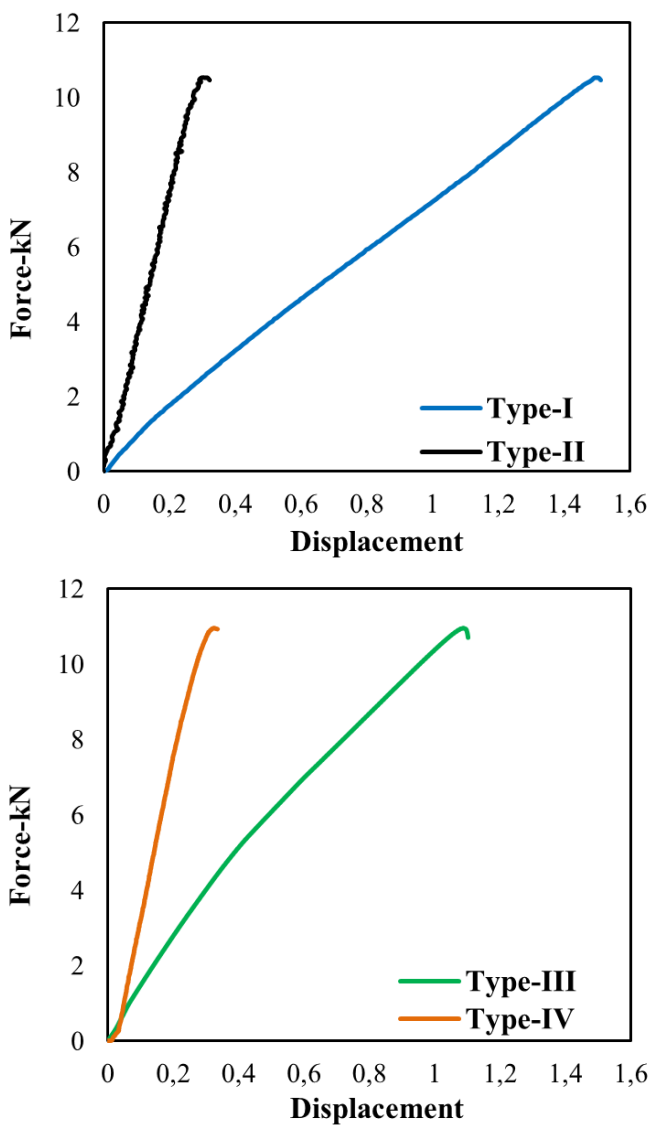

Figure 7. Comparison of the force-displacement curves obtained from the strokes and video extensometers of the tensile device a) Shimadzu AG-I (old device), b) Instron-5982 (new device). 
But in the means of the displacement, it was seen that, the difference of the data obtained from the stroke of the Shimadzu AG-I (the old device) and its extensometer is almost $380 \%$ and that difference for the Instron-5982 (the new device) was almost $227 \%$. Considering this situation, it is clearly understood that the value of the force obtained from the load cell of the calibrated tensile device is accurate while the displacement value obtained from the stroke of the device is erroneous. That difference is caused by addition of the displacement data due to the friction between the specimen and the jaw of the device during the test and the gaps in the connector elements of the device.

In comparison of two different devices (given in Figure 8), while the force values obtained from the load cells of the devices are close to each other, difference of the displacement values obtained from the strokes of the devices is almost 36\% (Figure 8a). That difference of the displacement data (difference between Type-I and Type-II) obtained from the both calibrated devices is caused by the wear in the jaws and other connector elements of the devices due to active usage. But, as it can be seen in Figure 8b, difference of the displacement data obtained from the video extensometers of the both calibrated devices is almost $2 \%$ which is an ignorable value. This shows that no matter what device (old, new or different brand) is, displacement data of the specimen should be obtained from the extensometer of the device (video or contact extensometer).
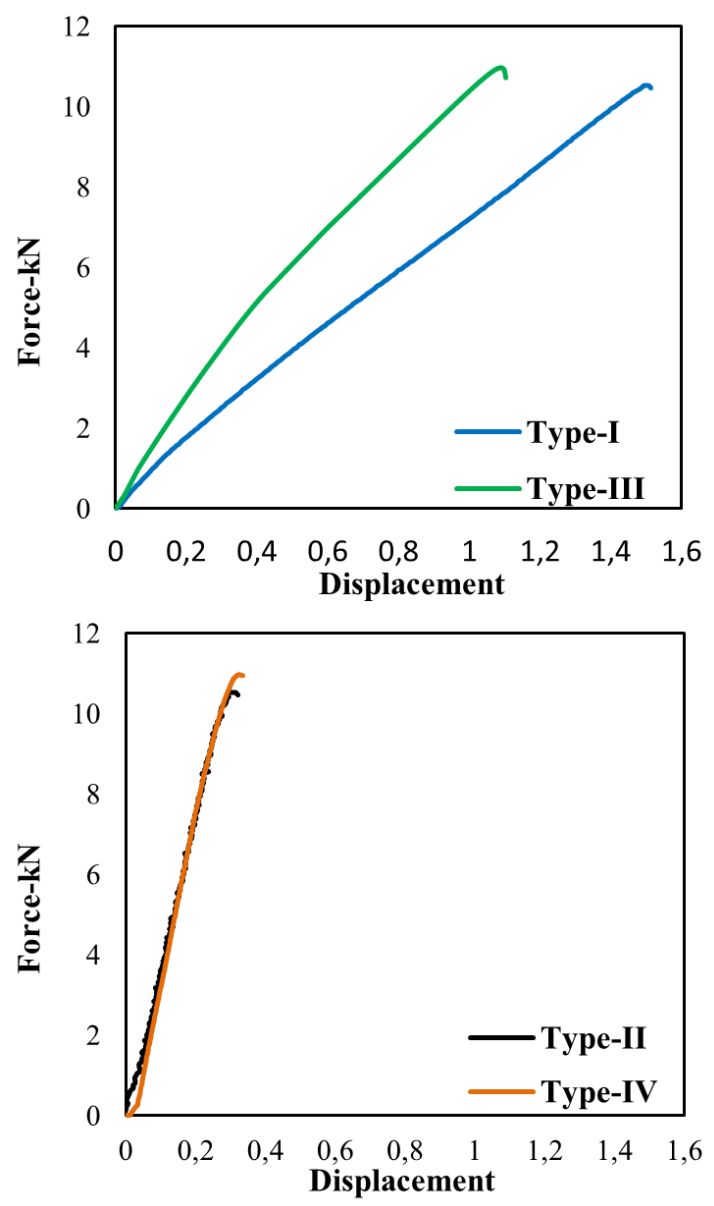

Figure 8. Comparison of two different tensile devices a) Data obtained from strokes, b) Data obtained from extensometers.
As it is shown in Figure 9, the force-displacement curves resulted from the numerical analysis are fairly compatible with the force-displacement curves (Type II and Type-IV) obtained from the extensometers of the both tensile devices. But in contrary, when the displacement data obtained from the strokes of the devices are compared with numerical analysis results, there is a significant difference (Figure 9a and 9b).
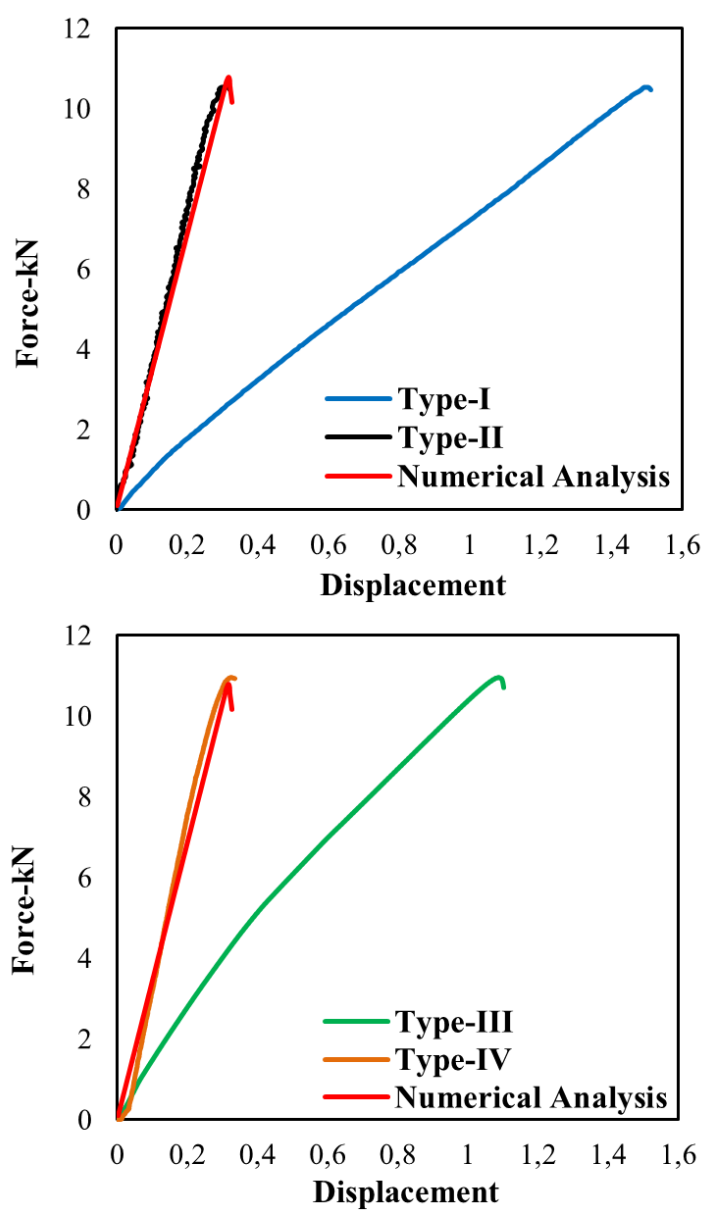

Figure 9: Comparison of experimental and numerical analyses results a) Shimadzu AG-I (the old device), b) Instron-5982 (the new device).

\section{CONCLUSIONS}

The result revealed in this study can be concluded as following;

- Difference of the displacement data obtained from stroke and extensometer of the tensile device varies between $227 \%$ and $380 \%$. Considering this situation, it is concluded that; force value of the test obtained from the load cell of the calibrated tensile device is accurate but the displacement data obtained from the stroke of the device is erroneous.

- While the force values obtained from the load cells of the tensile devices Shimadzu AG-I (the old device) and Instron-5982 (the new device) are similar to each other, the difference of the displacement data obtained from the strokes of the devices is almost 36\%. That difference of the displacement data obtained from the both calibrated devices is caused by the wear in the jaws and other connector elements of the devices due 
to active usage.

- Difference of the displacement data obtained from the video extensometers of calibrated tensile devices Shimadzu AG-I (the old device) and Instron-5982 (the new device) is almost $2 \%$ which is an ignorable value.

- The force-displacement curves resulted from the numerical analysis are fairly compatible with the forcedisplacement curves obtained from the extensometers of the tensile devices Shimadzu AG-I (the old device) and Instron-5982 (the new device).

\section{REFERENCES}

[1] Higgins, A., (2000). Adhesive bonding of aircraft structures. International Journal of Adhesion and Adhesives 20(5): 367-76, Doi: 10.1016/S0143-7496(00)00006-3.

[2] Edwards, K.., (1998). A brief insight into the selection and use of engineering adhesives for preliminary joint design. Materials \& Design 19(3): 121-3, Doi: 10.1016/S0261-3069(98)00011-9.

[3] Grant, L.D.R., Adams, R.D., da Silva, L.F.M., (2009). Experimental and numerical analysis of single-lap joints for the automotive industry. International Journal of Adhesion and Adhesives 29(4): 405-13, Doi: 10.1016/j.ijadhadh.2008.09.001.

[4] Goland, M., Reissner, E., (1944). The stresses in cemented joints. Journal of Applied Mechanics 66: 17-27.

[5] Srinivas, S.R., (1975). Analysis of bonded joints. vol. NASA TN D-.

[6] Tong, L., (1998). Strength of adhesively bonded single-lap and lap-shear joints. International Journal of Solids and Structures 35(20): 2601-16, Doi: 10.1016/50020-7683(97)00174-1.

[7] Adams, R.D., Peppiatt, N.A., (1973). Effect of poisson's ratio strains in adherends on stresses of an idealized lap joint. Journal of Strain Analysis 8(2): 134-9, Doi: 10.1243/03093247V082134.

[8] Adams, R.D., Peppiatt, n. a., (1974). Stress analysis of adhesive-bonded lap joints. Journal of Strain Analysis 9(3): 185-96, Doi: 10.1243/03093247V093185

[9] Chen, D., Cheng, S., (1983). An Analysis of Adhesive-Bonded Single-Lap Joints. Journal of Applied Mechanics 50(1): 109-15, Doi: 10.1115/1.3166976.

[10] Odi, R.A., Friend, C.M., (2004). An improved 2D model for bonded composite joints. International Journal of Adhesion and Adhesives 24(5): 389-405, Doi: 10.1016/j.ijadhadh.2001.06.001.

[11] Akpınar, S., (2019). The Effect of Adherend Thickness and Width on Fracture Behavior in Adhesively bonded Double Cantilever Beam Joints. European Mechanical Science 3(3): 83-7, Doi: 10.26701/ ems.566773.

[12] Narasimhan, R., Biswas, S.K., (1998). A finite element study of the indentation mechanics of an adhesively bonded layered solid. International Journal of Mechanical Sciences 40(4): 357-70, Doi: 10.1016/S0020-7403(97)00038-6.

[13] Harris, J.A., Adams, R.A., (1984). Strength prediction of bonded single lap joints by non-linear finite element methods. International Journal of Adhesion and Adhesives 4(2): 65-78, Doi: 10.1016/01437496(84)90103-9.

[14] Carpenter, W.C., Barsoum, R., (1989). Two Finite Elements for Modeling the Adhesive in Bonded Configurations. The Journal of Adhesion 30(1-4): 25-46, Doi: 10.1080/00218468908048192.
[15] Sheppard, A., Kelly, D., Tong, L., (1998). A damage zone model for the failure analysis of adhesively bonded joints. International Journal of Adhesion and Adhesives 18(6): 385-400, Doi: 10.1016/S01437496(98)00024-4.

[16] Andruet, R.H., Dillard, D.A., Holzer, S.M., (2001). Two- and three-dimensional geometrical nonlinear finite elements for analysis of adhesive joints. International Journal of Adhesion and Adhesives 21(1): 17-34, Doi: 10.1016/S0143-7496(00)00024-5.

[17] Marcolefas, S., Kostopoulos, V., Paipetis, S.A., (1991). Non-linear analysis of a metal-to-composite scarf joint. International Journal of Mechanical Sciences 33(12): 961-73, Doi: 10.1016/00207403(91)90052-5.

[18] Apalak, M.K., Engin, A., (2003). An investigation on the initiation and propagation of damaged zones in adhesively bonded lap joints. Journal of Adhesion Science and Technology 17(14): 1889-921, Doi: $10.1163 / 156856103770572043$.

[19] Magalhães, A.G., de Moura, M.F.S.F., Gonçalves, J.P.M., (2005). Evaluation of stress concentration effects in single-lap bonded joints of laminate composite materials. International Journal of Adhesion and Adhesives 25(4): 313-9, Doi: 10.1016/j.ijadhadh.2004.10.002.

[20] Li, W., Zhou, S., Shi, Z., Wang, X., Hu, P., (2017). Experimental and numerical analysis on fatigue durability of single-lap joints under vibration loads. The Journal of Adhesion 93(3): 187-203, Doi: 10.1080/00218464.2014.914927.

[21] Georgiou, I., Hadavinia, H., Ivankovic, A., Kinloch, A.J., Tropsa, V., Williams, J.G., (2003). Cohesive zone models and the plastically deforming peel test. The Journal of Adhesion 79(3): 239-65, Doi: 10.1080/00218460309555.

[22] Xu, Q., Nian, G., Shan, Y., Qu, S., Peng, H.-X., (2016). Numerical investigation on the loading-delamination-unloading behavior of adhesive joints. Composites Part A: Applied Science and Manufacturing 90: 45-50, Doi: 10.1016/j.compositesa.2016.06.021.

[23] Luo, H., Yan, Y., Zhang, T., Liang, Z., (2016). Progressive failure and experimental study of adhesively bonded composite single-lap joints subjected to axial tensile loads. Journal of Adhesion Science and Technology 30(8): 894-914, Doi: 10.1080/01694243.2015.1131806.

[24] Ribeiro, T.E.A., Campilho, R.D.S.G., da Silva, L.F.M., Goglio, L., (2016). Damage analysis of composite-aluminium adhesively-bonded single-lap joints. Composite Structures 136: 25-33, Doi: 10.1016/j. compstruct.2015.09.054.

[25] Campilho, R.D.S.G., Pinto, A.M.G., Banea, M.D., Da Silva, L.F.M., (2012). Optimization study of hybrid spot-welded/bonded single-lap joints. International Journal of Adhesion and Adhesives 37: 86-95, Doi: 10.1016/j.jjadhadh.2012.01.018.

[26] Campilho, R.D.S.G., Banea, M.D., Pinto, A.M.G., da Silva, L.F.M., de Jesus, A.M.P., (2011). Strength prediction of single- and double-lap joints by standard and extended finite element modelling. International Journal of Adhesion and Adhesives 31(5): 363-72, Doi: 10.1016/j.jjadhadh.2010.09.008

[27] Campilho, R.D.S.G., Banea, M.D., Neto, J.A.B.P., da Silva, L.F.M., (2013). Modelling adhesive joints with cohesive zone models: effect of the cohesive law shape of the adhesive layer. International Journal of Adhesion and Adhesives 44: 48-56, Doi: 10.1016/j.ijadhadh.2013.02.006.

[28] Gültekin, K., Akpinar, S., Özel, A., (2015). The Effect of Moment and Flexural Rigidity of Adherend on the Strength of Adhesively Bonded Single Lap Joints. The Journal of Adhesion 91(8): 637-50, Doi: 10.1080/00218464.2014.953674. 